\title{
Introducción a la poesía de Juan Larrea
}

PedRo Aullón de HaRo

U.N.E.D., Centro de Madrid

1. La obra poética de Juan Larrea (1895-1980) es construcción artística de modernidad absoluta. Su especificidad vanguardista no consiste en unos o en otros determinados rasgos más o menos fácilmente detectables sino en la realidad íntegra de su escritura; la cual si en un principio, como veremos, se realiza en formas que sin duda podemos tildar de creacionistas, en segundo término deviene discurso de coincidencia surrealista.

La redacción de los primeros poemas del autor de Versión Celeste converge y se acoge a la movilización literaria del Ultraísmo, contribuyendo desde la esfera de la creación poética al levantamiento de un aparato de vanguardia encaminado, desde sus inicios, a la destrucción de los sistemas estéticos modernista y castellanista (en lo esencial del 98) vigentes. Ese propósito de desintegración es el punto de partida inequívoco en la originación de cualquier fase del proceso estético de la Vanguardia histórica, desde el Futurismo italiano hasta el Surrealismo francés, puntos extremos y más aquilatados de la misma.

A partir de 1918, fecha en que se publica el primer manifiesto del Ultraísmo y comienzan a funcionar de manera radicalizada 
las tomas de postura provanguardistas en España, el inicio de la desarticulación de la retórica y el pensamiento poéticos de orden finisecular proyectados por el idealismo romántico (Decadentismo, Prerrafaelismo, Simbolismo, Modernismo, etc.), es incontrovertible. Ciertamente la vieja estética seguirá existiendo y desarrollándose, pero reducida ya, si no al silencio, sí a un segundo plano del cual sólo habría de emerger, en tanto que significativa, de forma ocasional y muy evolucionada (v. gr.: heteroforme en The Waste Land de Eliot, recontinuadora en Cántico de Guillén, etc.), a veces asumiendo una perspectiva de integración de la que en nuestro país ya había dado buen ejemplo Juan Ramón Jiménez en 1917 con su influyente Diario de un poeta recién casado ${ }^{1}$.

El desenvolvimiento de la revolución vanguardista española -siempre incipiente, sobre todo en sus primeros tiempos-, tuvo una doble fundamentación: Futurismo y Creacionismo. De una parte, la violenta presencia programática de Marinetti desde 1909, que ya en en ese mismo año había tenido entre nosotros eco considerable como consecuencia de la traducción realizada por Gómez de la Serna del primer manifiesto márinettiano en su revista Prometeo. De otra, la presencia en Madrid de Vicente Hui-

1 Las intromisiones estéticas en general constituyen un fenómeno de expresión artística sin el cual nunca se hallará justa respuesta a los procesos de conjunción, disyunción o ruptura del arte - en nuestro caso la poesía - según queda establecido en el devenir de los movimientos literarios, plásticos, musicales, etc., particularmente en lo que atañe al decurso de las formaciones culturales revolucionarias anticlásicas que se originan con la irrupción del Romanticismo, el Simbolismo y las subsiguientes fases que se corresponden con la Vanguardia histórica. He estudiado el problema de las intromisiones bajo el concepto de heteromorfia haciendo ver, sobre la base de la obra de J. R. Jiménez, los modos de imbricación relevante en que las mismas se resuelven: «Determinación de la heteromorfia Modernismo / Vanguardia», en Universidad y Sociedad, 1 (1981), pp. 107-120. En realidad, mi intento de presentar uno de los posibles paradigmas de análisis es pormenorizadamente desglosable en cuanto aplicación a los distintos niveles de análisis lingüístico en que cabe descomponer el discurso poético. No se ha de olvidar, por otra parte, la extraordinaria extensión, particularmente en lo que se refiere a la estética simbolista (prerrafaelista, modernista, etc.), en que se disponen las formas de superposición estética no heteroformes. Para la importantísima pervivencia de la expresión simbolista, perfectamente trabada como sistema poético tópico, véase el breve pero sugerente estudio de Ann Balakian, El movimiento simbolista, Madrid, Guadarrama, 1969. Respecto del particular caso españoi de la doble vertiente Modernismo y 98 en lo que tiene que ver con la ruptura de la Vanguardia, puede consultarse el estudio preliminar que antepongo a mi edición Poesía de la Generación del 98, Madrid, Taurus, 1984. Finalmente, en lo que tiene que ver con las superposiciones de tipo vanguardista, en el presente artículo se podrán advertir las atingencias Creacionismo/Surrealismo, en lo que a Larrea se refiere. 
dobro, quien hizo imprimir en casa Pueyo (1918) algunas de sus composiciones más importantes (Ecuatorial...) y expuso a los poetas españoles mediante la charla personal y conferencias su teoría estética. Hablando pronto y esquemáticamente, así fueron las cosas. El hecho es que en 1918, como ha escrito GonzálezRuano, «nadie sabía en España quién era Reverdy, ni siquiera quién era Apollinaire» ${ }^{2}$. No es de extrañar, por tanto, que el pensamiento poético futurista y, sobre todo, el del Creacionismo huidobriano, constituyeran el principio informador básico de los trabajos programáticos intentados por Juan Larrea en $1926 \mathrm{y}$, en especial, por Gerardo Diego desde 1919, los dos grandes poetas creacionistas españoles.

La concepción literaria ultraísta, más vagamente intencional que de efectivo contenido teórico y resultados prácticos, convirtióse en una amalgama totalizadora dentro de la cual se confundía la poética huidobriana con cualquiera otra distinción vanguardista. Fue un abanderamiento propiciado por Rafael Cansinos-Asséns, quien supo recoger el estado de opinión artística más o menos latente de ciertos sectores en ese momento, después removido principalmente por el muy discutible Guillermo de Torre $^{3}$.

2. Larrea comenzó a publicar sus poemas, juntamente con Diego y a petición de éste, en la sevillana revista ultraísta Grecia. Después, sobre todo, en Cervantes. En Grecia aparecieron, entre diversos nombres en su absoluta mayoría de segunda fila o ya definitiva y justamente olvidados, versiones de poemas franceses de Vicente Huidobro, Apollinaire, Max Jacob o Pierre Reverdy a cargo de Cansinos-Asséns y Guillermo de Torre. De lo que se trataba era de ofrecer una información textual de urgencia para las necesidades del momento. Algo similar sucedió con Cervantes en la época en que la dirigiera Cansinos.

2 Cf. «Vicente Huidobro», en el vol. de René de Costa (ed.), Vicente Huidobro y el creacionismo, Madrid, Taurus, 1975, p. 69.

3 Espero ofrecer pronto un detallado estudio histórico-literario y teórico-poético acerca de estos problemas en un volumen titulado La Concepción de la Modernidad en la Poesía española. 
Entre los vanguardistas españoles hubo poetas que empezaron a realizar sus trabajos dentro de la Vanguardia (es el caso de Larrea); y otros, los más, que procedían de la estética modernista y de la noche a la mañana cambiaron de rumbo, o, en otro caso, habían evolucionado coherentemente (v. gr., Antonio Espina, o Lasso de la Vega, el más interesante de éstos). Fenómeno muy particularizado es el de la obra de doble vertiente, vanguardista y tradicional, de Gerardo Diego, a quien desde luego no se dudó en atacar por esa circunstancia (así Cansinos en un artículo que pasó a integrarse en sus volúmenes de La Nueva Literatura, o Fernández Almagro en la revista Alfar).

En la formación poética de Larrea existieron dos hechos relevantes que importa notificar. El primero de ellos es la visita que le hizo Diego en Bilbao la primavera de 1919. Con tal motivo - ha contado David Bary valiéndose de informaciones que le diera el propio Larrea-, "Gerardo lleva consigo tres poemas de Huidobro, que ha copiado a mano, escritos en un lenguaje inusitado. Larrea los lee con gran interés, así como la revista Grecia, que le presta Gerardo». Asimismo añade Bary que "para Larrea la lectura de esos textos entonces y de Poemas árticos el mes siguiente, que compró el libro en Madrid, fue un acontecimiento decisivo. Cambió su vida. De pronto vio, según me dijo en 1970, el cielo abierto, palabras que hay que leer, creo, con toda la atención que merecen. La vida empieza a tener sentido. De un trazo escribió un poema de estilo algo huidobriano, pero cuyo contenido, extraño y original, expresaba preocupaciones básicas para toda su vida y obra» ${ }^{4}$. Dicho poema, que abre Versión Celeste, es «Evasión»; el mismo Larrea ha explicado su contenido premonitorio y conformación mitológico-simbólica ${ }^{5}$. El último de sus versos: "Aún tengo que huir de mí mismo», engarza con la decisión de abandonar la lengua española como instrumento de expresión poética por parte del autor. Es un huir que deviene perse-

5 En su artículo «Cartas de amparo para un poema», en Poesia, 5-6, invierno 1979-1980, pp. $7-15$. 
cución constante de un más allá que rige ostensiblemente toda la obra y la vida del poeta. Uno de los cauces fundamentales de cuya búsqueda hallará Larrea en el conocimiento y la experiencia herméticos, aspecto que vertebra su pensamiento con el hermetismo subyacente en la poética huidobriana y en general la tradición literaria de la Modernidad desde sus orígenes románticoalemanes. Son problemas extensos sobre los que no entretendré aquí mis argumentos ${ }^{6}$. Resultado teórico de todo ello es la considerable dedicación ensayística larreana desarrollada básicamente en Rendición del Espíritu (1943), La Espada de la Paloma (1956), Razón de ser (1956) y Teleología de la cultura (1965), libros de peculiar argumentación y envergadura ${ }^{7}$.

El otro punto decisivo en la formación del pensamiento poético de Larrea fue su contacto directo con Huidobro, establecido con motivo de una conferencia que en 1921 vino el chileno a dar en Madrid, y a la que asistió en compañía de Gerardo Diego. A partir de entonces se fraguó entre los tres una fidelidad inquebrantable.

Larrea, que había estudiado el idioma francés desde la infancia, no debió de tener muchas dificultades a la hora de poner a prueba uno de los principios teóricos creacionistas que ya había llevado a la práctica Huidobro y, por otra parte, como ya he advertido, funcionaba en una dirección de desprendimiento y búsqueda coincidente con el espíritu que animaba al poeta. Desde el punto de vista de la traductibilidad del texto poético, Huidobro señalaría en su ensayo programático El Creacionismo que «es difícil y hasta imposible traducir una poesía en la que domina la importancia de otros elementos. No podéis traducir la música de las palabras, los ritmos de los versos que varían de una lengua a

6 Ya he tenido oportunidad de analizar el establecimiento de las líneas maestras de la poética y el pensamiento modernos en La poesía en el siglo XIX, Madrid, Playor (LCLE), 1982; y «La construcción del pensamiento crítico-literario moderno", en mi ed. Introducción a la Crítica literaria actual, Madrid, Playor, 1984.

7 Son textos que sin duda cuentan como reflexión en amplio sentido antropológico-filosófica con un raro e importante lugar entre la producción ensayística de lengua española. Cf. $P$. Aullón de Haro, El ensayo en los siglos XIX y XX, Madrid, Playor (LCLE), 1984. 
otra; pero cuando la importancia del poema reside ante todo en el objeto creado, aquél no pierde en la traducción nada de su valor esencial» ${ }^{8}$. Diego también abordó el problema en distintas ocasiones. En «Retórica y Poesía», artículo publicado en Revista de Occidente ${ }^{9}$, asociándolo a la relación Poesía/Música; en otro lugar arguyendo «la indiferencia del instrumento idiomático» ${ }^{10}$ dentro de la poética compartida por los creacionistas. Finalmente, refiriéndose a la conducta del autor de Versión Celeste al utilizar la lengua francesa, Diego ha explicado que «para comprenderlo mejor, es preciso, indispensable conocer a fondo la poética de Larrea. En gran parte yo la comparto y he confesado que le debo lo esencial de la mía. En la poética que juntos profesamos en nuestra juventud y que sigue fundamentalmente vigente para los dos, el valor poético de la palabra, del poema, no reside tanto en su piel, en su sonoridad y matices lingüísticos intraducibles, sino en su significado. Tanto nosotros como Vicente Huidobro estimábamos que lo profundo de la poesía es lo que tiene de traducible. Si un poema sólo posee valores intraducibles no es poema cabal, es poema medio vacío, impotente» ${ }^{11}$. Son consideraciones las de Diego que, en el marco global de la poética creacionista, adquieren plena significación al ser analizadas bajo la perspectiva que en otra ocasión he denominado mediante el concepto de «utopía artística» ${ }^{12}$.

3. El volumen que aloja la obra poética de Larrea, Versión Celeste $^{13}$, alberga, pues, textos en lenguas española y francesa.

8 Cf. V. Huidobro, Obras Completas, Santiago de Chile, Edit. Andrés Bello, 1976, t. I, p. 736.

9 Núm. XVII (1924), p. 285.

10 Véase G. Diego, «Vicente Huidobro (1893-1948)», en R. de Costa (ed.), Vicente Huidobro y el creacionismo, cit., p. 20.

Cf. «Larrea traducido», en J. Larrea, Versión Celeste, Barcelona, Barral, 1970, p. 13.

12

Se trata de mi estudio «La Teoría poética del Creacionismo», que aparecerá en Cuadernos Hispanoamericanos (octubre, 1985), y al que necesariamente remito. ñol de los poemas franceses son de los citados y Carlos Barral. 
Metal de voz, su primera parte, contiene poemas en español; Ailleurs en francés; Oscuro Dominio consta de composiciones en verso y prosa de nuevo en castellano; Pure Perte todas en francés excepto una («Espinas cuando nieva»); y Versión Celeste -que da título general al volumen-, el más extenso junto con el anterior, todas en francés. A ellas, para conjuntar la totalidad de la poesía larreana, sólo habría que añadir tres francesas, que se recogen en un apéndice de la citada edición, y unas cuantas en su momento aparecidas en revista y que, por voluntad del poeta, no han sido en este volumen recopiladas ${ }^{14}$.

Metal de voz comienza con textos de la primera época del Ultra escritos desde la primigenia experiencia poética creacionista de Larrea. Ciertamente es difícil de establecer la linde indicativa exacta que marca la transgresión de los límites estrictos de los principios del creacionismo hacia un discurso formalmente de coincidencia surrealista en ese poemario. Antes bien habría que pensar el problema desde el punto de vista de una progresiva evolución creacionista de la escritura, cosa mucho más razonable y realista. Con todo, el examen de los textos nos va a permitir el establecimiento de una distinción cuando menos válida a nivel metodológico o convencional, y que nos será francamente útil entendida como superestructura desde dentro de la cual emprender el análisis. En este sentido parece incuestionable que «Razón» es el poema que identifica la línea ecuatorial entre un sector de neta dependencia estética creacionista y otro de transgresión de los postulados iniciales de la praxis de la misma. Por otra parte, tampoco hay que dejar de lado el hecho de que al proceso cronológico de la creación de Metal de voz corresponde, en paralelo, otro tanto con la poesía de Huidobro. Esto quiere decir que en un determinado momento del decurso de la escritura de Larrea se hace patente el distanciamiento de las formalizaciones poemáticas típicamente huidobrianas; esto es las identificables con los libros del chileno correspondientes a 1918 y años próximos a esa fecha. Sin embargo puede que no ocurra así en lo que se refiere a del diario El País, núm. 51, 12 de octubre 1980, p. 7, con motivo de la muerte del poeta. 
los trabajos posteriores del autor de Tour Eiffel, hasta la fecha de 1932 en que Larrea deja de escribir poesía. Y no necesariamente hay que hablar de libros en lo que atañe a lo dicho de Huidobro, pues el español estuvo literalmente al tanto de la actividad poética del chileno. De lo que se sigue, en efecto, que no es mi propósito generalizar la distinción más arriba propuesta sino, por el contrario, utilizarla dentro de sus limitaciones sabidas.

Los poemas agrupados tras «Razón» muestran: a) una distribución espacial del texto ya no dependiente de las formas prototípicas de la influencia huidobriana centrada en 1918; b) la superación de la técnica de construcción de imágenes y metaforizaciones, en su valor primigenio creacionista de autónomas, pasando a integrarse ahora en un propósito ordenador superior, total, de discurso cuya formalización es concebida mediante una diferente ejecución de estructuras sintácticas y estrófico-espaciales que tienden a una mayor cohesión discursiva.

Junto a «Razón», "Centenario», el poema que le precede, es el antecedente más claro de transgresión de los procedimientos primigenios de técnica compositiva creacionista. En él las formas de discurso han cambiado ya ostensiblemente; su proceder constructivo general se apoya en un motivo temático único, el llamado Virgilio, personaje sobre el cual versa el texto y al que se habla e interroga. Caso bien distinto es el del anterior "Cosmopolitano", composición mucho más extensa basada en la yuxtaposición de cuadros temáticos imaginistas que dimanan de la contemplación de la ciudad, y cuyo modelo es sin lugar a dudas localizable en el Ecuatorial de Huidobro. Lo mismo cabe decir del poema de Gerardo Diego titulado «Gesta», de Imagen (1922). Pienso que por medio de esos tres textos puede establecerse el mejor ejemplo de comunidad poemática contextual entre los mismos tres grandes poetas del creacionismo.

A diferencia de Diego, Larrea no continuará experimentando durante los años siguientes en el terreno de la primigenia concepción organizativa poemática creacionista y sus estrechas imbricaciones con el Cubismo. Por otra parte, el componente lúdico, usualmente vanguardista, siempre utilizado por Diego de modo 
manifiesto, en Larrea puede observárse que se reduce (y de forma mucho más fría: sin implicaciones humorísticas) a Metal de voz. Larrea tenderá a una isomorfia textual y a una normalizada gramaticalidad morfosintáctica en la construcción del discurso que, en consecuencia, le hará alejarse en lo sucesivo de las formas de disposición caligramática, aun moderadas, tales las que frecuentemente realizaba Diego y él mismo empleó en escasa medida en sus primeros poemas y tan sólo en «Estanque» planteó de manera plena. Así pues, podrá comprobarse una conducta poética, externamente al menos, en coincidencia con lo preconizado por los surrealistas franceses: la normalización de las estructuras sintácticas y de la disposición espacial del texto. Es postura que Breton instrumentó para, de paso, alejarse de las formalizaciones plástico-textuales y de la poética programática violentamente desestructuradoras del futurismo italiano y, en medida no despreciable, confluyentes con la poesía más gráfica de Apollinaire, a quien el papa surrealista quiso desterrar a un segundo plano, invocando sólo, como si fuesen excluyentes, el magisterio inmediato de Pierre Reverdy ${ }^{15}$.

Ante poemas como los antecitados «Centenario» o «Cosmopolitano» de Larrea, "Gesta» de Diego, o el Ecuatorial huidobriano, pudiera decirse, como ha hecho inteligentemente Cano Ballesta refiriéndose a "Centenario» de manera específica, que «el cosmos adquiere sustantividad frente al yo o al tú, convertido en sujeto pasivo, receptor, que vibra ante las sensaciones que le llegan y es capaz de reflejar las maravillas del mundo" ${ }^{16}$. Es des-

15 Si no otra cosa, convendrá recordar que el concepto poético de imagen se halla en los principios teóricos de la poesía futurista, así como del Imaginismo, el Cubismo, el Creacionismo (Huidobro, Diego) y el Surrealismo. Lo cual estatuye un punto de partida común que habrá de ser considerado de distintos modos. Cf. F. T. Marinetti, Teoría e Invenzione futurista, ed. Aldo Palazzescchi y Luciano De Maria, Verona, Mondadori, 1968; Ezra Poud, El arte de la poesía, México, Joaquin Mortiz, 1970; Pierre Reverdy, Nord-Sud, Self Defence et autres écrits sur l'art et la poésie, París, Flammarion, 1975; André Breton, Manifiestos del Surrealismo, Madrid, Guadarrama, 1974, 2. ${ }^{a}$ ed. Nuevamente he de remitir a mi estudio, aún en prensa, «La Teoría poética del Creacionismo», del cual el presente artículo es de alguna manera un complemento, pues va referido a la poesía y no a la especulación teórico-literaria.

16 Cf. J. Cano Ballesta, La poesía española entre pureza y revolución (1930-1936), Madrid, Gredos, 1972, p. 17. 
de luego cosa generalizable sobre una gran cantidad de importante poesía española de la época. Ahora bien, el argumento no conviene hacerlo extensible de manera absoluta al caso concreto de Larrea (esto es fácil de percibir ya desde «Evasión», primer poema de Metal de voz y al cual he aludido con anterioridad), habida cuenta del carácter profundo o transcendente "pretextual» a partir del cual se genera el texto; del carácter en ocasiones hermético, si se quiere, que prevalece a la trasposición lingüística y cuya razón estriba en el sentido último de una experiencia de índole mística. Experiencia para la cual la realidad representada vale en cuanto que expresión de un proceso espiritual de "descripción» interna, descomponible o no en significaciones «objetivas». Siendo así que mucha precaución haya que tener en el momento de trasladarse, dentro de la poesía de Larrea, de un análisis de sesgo formal a otro de interpretación semántico-temática; porque a fin de cuentas la apreciación de significaciones directas -en lo que permite una poesía cuyo mayor volumen es de coincidencia lingüística surrealista- que presenta el discurso podría quedar al margen del sentido anterior, complejamente implícito, que lo dirige. Ello no quiere decir sin embargo que vayamos a prescindir de constatar significaciones en primera instancia, $o$ incluso simbolizaciones, pero siempre sobre terreno en el que dispongamos de una seguridad suficientemente manifiesta. Ponen sobre aviso de lo argumentado referencias del tipo de, por ejemplo, «el antes y el después» (Oscuro Dominio, p. 120); «el corazón de otro mundo» (O.D., 123); "corderos pseudoeternos» (O. $D ., 130$ ), etc. Nos referimos ciertamente a textos en los cuales al menos algunas de sus fases son construcciones alegóricas de considerable complejidad, más difíciles de dilucidar que Metal de $v o z$, donde aparece «la esfinge», elemento bien asentado en diversas formaciones culturales y estudiado por C. G. Jung en Símbolos de transformación. Baste lo dicho, pues no se intentará aquí una interpretación descriptiva de tales composiciones.

Procede observar que la lengua artística de Larrea, tras su fase de rodaje creacionista, opera una evolución cuyos resultados, en términos puramente lingüísticos, cabría designar como surrea- 
listas. Se lee, verbigracia, en la primera estrofa de «Tierra al ángel cuanto antes» $(M . V ., 67)$ :

\author{
Durmiendo por tributo de flor a ya altos trigos \\ ángel en puertas de huracán sin nieve \\ arbusto a más alzar manos de eclipse \\ pies ardiendo al revés de los días yo os siento \\ porfiar de cautela en la cercada angustia \\ y deshojar coronas de mundo en mis salinas.
}

No existe, pues, una organización asociativa lógica en el discurso. Asimismo, el prodigio verbal y su naturalidad composicional es fácilmente discernible como fenómeno de los más portentosos de nuestra literatura. Ha escrito Paul Ilie - a quien voy a citar en extenso- que «al colocar una distancia máxima entre dos realidades yuxtapuestas, el poeta fabrica absurdidades que parecen involuntarias y productos del azar. El resultado es una poesía que surge con el aspecto de una ejecución estética. Es intrincada, autosuficiente y ostensiblemente sin un significado básico más profundo que el valor externo de la forma misma. Como todos los poemas resultan dislocados y lógicamente absurdos, parece no tener objeto buscar un vínculo entre significado y absurdidad. $\mathrm{Y}$ a pesar del punto de vista obviamente personal, los métodos del simbolismo psicológico se vuelve ineficaces, si no cuestionables, en virtud de la ausencia de pautas imaginísticas claras. Así, más que la mayoría de los poetas surrealistas, Larrea resiste la comprensión tanto en términos metafóricos como emocionales. El carácter lírico emocional de su obra es elusivo e inconsistente. Mientras que otros poemas traicionan absurdidades superficiales por medio de imágenes obsesivas o estados de ánimo que lo penetran todo, Larrea muestra sólo superficies, cada cual pulida de un modo distinto y no obstante todas evidentemente cortadas en la misma cantera de absurdidad. Como su credo estético rechaza los juegos estéticos por sí mismos, constantemente nos quedamos con la duda de no saber a qué obedece todo esto, de «¿Qué está tratando de decir?» ${ }^{17}$.

17 Cf. Paul Ilie, Los surrealistas esjıñoles, Madrid, Taurus, 1972, p. 304. 
Valga la larga cita de Ilie, pues pone en línea los problemas fundamentales de la poética larreana. A mi juicio, la poesía de Larrea es resultado de una génesis de pensamiento emparentable sin duda con estados de ánimo frecuentemente no susceptibles de delimitación. En este sentido su trabajo literario pienso que está concebido de manera asociable a lo por él mismo explicitado en el manifiesto Presupuesto vital en términos de que «para nosotros sólo nuestro tiempo existe»; es decir, una intencionalidad focalizada en el tiempo presente y, en consecuencia, no elegíaca, ajena al propósito de el recuerdo o la poetización de la memoria. Ello sería, si bien se mira, un modo de transcendentalización de lo inmanente -opuesto al prototípicamente romántico- como una de las alternativas creacionistas de transcendencia a la intranscendencia antirromántica de la Vanguardia. Lo cual, desde un punto de vista psicológico así como puramente artístico, constituye un planteamiento de repercusiones extraordinarias. Algo semejante, en cuanto a la relación transcendencia/intranscendencia, sucede bajo razón artística en la teoría poética de Gerardo Diego, y naturalmente de Huidobro. Por otra parte, son de considerar también en el citado manifiesto las encarecidas indicaciones de Larrea acerca de la superación del dualismo romanticismo/clasicismo y, en confluencia con la programática surrealista - raro contacto entre ambas estéticas-, el no divorcio entre inteligencia y sensibilidad. Ambas, conceptuaciones de raíz huidobriana y en última instancia procedentes de la tradición hermética ${ }^{18}$.

En lo que hace concretamente al fragmento transcrito de Ilie, hay que empezar por decir que peca de generalización. Puede afirmarse sin vacilaciones: existen poemas que sí «poseen un significado básico más profundo que el valor externo de la forma misma». Por ejemplo, «Razón»:

18 Véase Presupuesto vital (originalmente publicado en la revista Favorables París Poema, 1, julio de 1926, incluido en Versión Celeste, cit., pp. 307-312. 
Sucesión de sonidos elocuentes movidos a resplandor, poema es esto

$$
\text { y esto }
$$

$$
\text { y esto }
$$

Y esto que llega a mí en calidad de inocencia hoy, que existe

$$
\text { porque existo }
$$

y porque el mundo existe.

y porque los tres podemos dejar correctamente de existir.

A su vez, es abusar de nuevo de la generalización el sostener que «los métodos del simbolismo psicológico se vuelven ineficaces», pues no siempre es así; además de que los del simbolismo hermético funcionan no pocas veces. Recuérdese el simbolismo de la expresión gráfica del título - anteriormente reproducidodel segundo de los poemas de Metal de voz, o que el primer sustantivo en ese texto enunciado es el ya referido «esfinge». Si recurrimos al ya citado «Cosmopolitano», es posible argüir términos de ascendencia mística (Juan de la Cruz) como «majadas» (v. 22) u otros de Oscuro Dominio («verdura») o de eco bíblico («ciudad fruta mordida»). Por otra parte, es preciso convenir en la existencia de composiciones que brindan una incontrovertible comprensión intuitivo-emocional y simbólica. Acaso el ejemplo más inequívoco sea el que ofrece «Diente por diente, III», de Oscuro Dominio, que constituye un doloroso alegato contra la sociedad industrial en el marco de copresencia de una realidad de mecanización y proletariado urbano perceptible, indudablemente, en la consideración del destino del hombre anónimo, en el discurrir de una sociedad que no hace nada por él sino más bien todo lo contrario.

El contexto urbano está presente en la poesía de Larrea de la manera apuntada, pero también en su más plena funcionalidad vanguardista, como representación del mundo vertiginoso de las relaciones urbanas y la obsesión fabulosa por la multiplicación ingente de objetos, máquinas y artefactos que el desarrollo de las grandes ciudades y la industria consigo traen. Se asimilan así los 
conceptos de multiplicidad y simultaneidad, bien reconocibles en una estructura compositiva como la de "Cosmopolitano". No obstante, Larrea accedió además a una indagación de los contextos urbanos que lo alejan de los habituales postulados de la vanguardia. Léase una excelente interpretación de la ciudad desolada en «Diente por diente, II» $(O . D ., 128)$ y, en un siguiente paso, "Atienza» - del mismo libro-, poema de ribetes alegóricos no difícilmente comprensibles cuyo tema es la desaparición humana de un pueblo y que representa una visión de lo que significaría para el hombre de conducta urbana la vida en el deshabitado Atienza.

Las últimas citadas son composiciones en prosa; es decir, textos en los cuales la construcción poemática se sirve de la prosa como resorte de modernidad creado en cuanto género por el Romanticismo anglogermánico (no francés, según suele decirse). Formalización prosística de la poesía muy utilizada por la vanguardia surrealista y que en España ya disfrutó de carta de naturaleza propia en el pasado siglo independientemente de las experiencias en lengua francesa. Dentro del ámbito de la poesía surrealista española no pueden olvidarse los trabajos en el género de Vicente Aleixandre (Pasión de la tierra) y José María Hinojosa (La flor de California), quienes junto a Larrea describen la aportación vanguardista fundamental al poema en prosa de nuestra lengua ${ }^{19}$.

Sin embargo, el grueso de la obra poética de Larrea está escrito en verso, en verso formalmente de coincidencia surrealista, y no ya su poesía francesa sino la misma española, en la que, como dijimos, tiene lugar la transición de los primigenios procedimientos composicionales creacionistas a otros, aparentemente al menos, en buena parte de orden surreal. El autor de Versión Celeste tuvo relación en París con los poetas surrealistas franceses; él mismo ha asegurado que conoció a la mayoría de ellos y aun previamente supo incluso de las actividades dadaístas. Su poesía es, 
probablemente, la más importante de la vanguardia española. No obstante, Larrea dice y repite: « $i$ Yo no fui surrealista nunca!»; y si se le interroga, «-iPero cómo dice usted eso? Pero si todo el mundo sabe que es usted un surrealista de fondo. ;Lo sabe todo el mundo!», contesta que «la gente habla, dice, no sa$\mathrm{be}, \mathrm{ja}, \mathrm{ja}, \mathrm{ja}$ » ${ }^{20}$. Refiriéndose a los ultraístas aduce: «lo que hacían era tomar las partes exteriores, externas, de las posibilidades de un más allá. Pero no iban a un más allá, mientras que yo tenía necesidad profunda de ir a un más allá, porque tenía así planteada mi personalidad, probablemente porque provenía de raíces religiosas tenía necesidad de tal» (Ibid.). No parece necesario redundar mediante otras citas u observaciones, pues lo que parece cierto es que el poeta se introdujo en una trayectoria de experiencia interior que de ningún modo quiere que, bajo la exclusivista etiqueta de surrealismo, sea metida en camisa de fuerza e integrada en los movimientos tradicionalmente dispuestos por la historia de la literatura, de la que él repugna. Con todo, cabe preguntarse, ¿hubiese sido posible la construcción del discurso artístico de Larrea sin la existencia pareja del lenguaje surrealista? De otra parte, la intimidad de nuestro poeta con el Surrealismo ha quedado suficientemente reflejada en El surrealismo entre viejo $y$ nuevo mundo (1944), después asimilado a Del Surrealismo a Machupicchu (1967), y César Vallejo y el Surrealismo (1976), libro fruto de una acerada polémica y que gira en torno a la fiel dedicación larreana para con la obra del gran poeta peruano, quien fuera su amigo entrañable en su época parisina y coeditor de la revista Favorables París Poema ${ }^{21}$.

El verso formalmente surrealista de Larrea concibe especiales peculiaridades de interés. Aquello que quizás más llama la atención del lector es su señaladísimo tono de convicción discursiva, la enorme condición de veracidad que sus palabras desprenden,

Cf. la entrevista realizada por F. Maraña, «J. L. Visión y Apocalipsis», en Kantil, 9, mayo (1978), s. p.

21 También convendrá recordar los distintos trabajos de Larrea sobre poesía recopilados en el vol. Torres de Dios: Poetas, presentación de José-Miguel Ullán, Madrid, Editora Nacional, 1982. 
por lo demás fenómeno poco común entre los poetas surrealistas de cualquier lengua. Ha apreciado Paul Ilie cómo «la fuerza de la lógica puede ser aún más implacable cuando la sintaxis y la solemnidad epigramática figuran en declaraciones absurdas ${ }^{22}$, y recurre a la ejemplificación valiéndose del verso «En el país de la risa la ceniza precede al fuego" $(O, D ., 127)$. Ilie hace ver cómo se produce una inversión de la secuencia causa-efecto y señala, además, que «su formulación sitúa la ley de la causalidad en el contexto moderno de la risa surrealista» (Ibid.). Empero, llegados a este punto, se hace necesario resaltar el error a que en último término puede conducir ese análisis. Nada más alejado de un texto como el del que procede el ejemplo citado ( Diente por diente, I») que un posible acceso de humor o de risa. Sí acude Larrea de alguna manera a la nota intranscendente en ciertas ocasiones, ya sea mediante los elementos de la realidad que representa, ya sea mediante afirmaciones de ostensible sentido irónico, que sabido es funcionan a modo de contraste semántico (esencial en la poesía vanguardista) y son, por sí mismas, un procedimiento harto frecuente dentro de la poesía moderna. Es el caso de un verso que se lee en el mismo poema (verso que se hizo popular en los ambientes literarios de la época, según ha contado Moreno Villa): «Un café nunca está lejos»; pero adviértase que aparece inserto en un contexto de profunda gravedad surrealista, no por ello exenta de rasgos ironizantes, cuyos últimos versos se pronuncian en el sentido de que los hombres son «Como eclipses parciales / Como solos de arpa / Como tiros al aire / Como cerillas».

Se ha dicho con acierto de Larrea que «la supremacía del poeta sobre todo lo creado, merced a su sueño revelador, es evidente y le permite asociar elementos abstractos y concretos con una facilidad escalofriante» ${ }^{23}$. En "Afueras periódicas» $(M . V ., 66)$ puede leerse: «Tu silueta forma parte de las precauciones frívolas del equinoccio»; y también: «Por su propio peso la tristeza baja

23 Véase F. Aramburu, «J. L.: un mesías emplumado y su versión celeste», en Kantil, núm. cit., s. p. 
los grados de la escala social / entre los gritos profesionales del horizonte». O véase este otro conspicuo ejemplo $(M . V ., 67)$ : "Caen los ojos y el polvo se despierta al recuerdo». Por otro lado, a propósito del citado verso que comienza «por su propio peso", interesa específicamente hacer notar la frecuente utilización larreana de giros y clichés lingüísticos, lo cual contribuye decisiva y eficazmente a la consecución de un tipo de lenguaje pleno de convicción y veracidad. El procedimiento, lejos de manifestarse tan sólo por medio de formas normalizadas, reviste peculiaridades dignas de estudio. Así se desprende, por ejemplo, de un poema como «Espinas cuando nieva» (Pure Perte, 220), donde sobre la base de la metáfora lexicalizada «a flor de piel», se construyen las variantes de conmutación «a flor de agua» y «a flor de invierno» (vv. 5 y 6). Distinta actuación, aunque de idénticos resultados en la impronta referida de convicción discursiva, es el empleo de formas fraseológicas automatizadas del tipo de «por toda respuesta» $(M . V ., 52)$ o la adverbialización «a grandes rasgos» $(M . V ., 73)$. O el diferente caso de la conmutación léxica deshabitualizadora «fotógrafo furtivo» $(M . V ., 53)$, frente al sintagma usual "cazador furtivo». En fin, diríase que Larrea establece un discurso de amplísimo eje combinatorio de automatismo y desautomatización mediante el cual obtiene un raro equilibrio de expresiones semánticamente extremadas que permanecen dentro de los márgenes de la gramaticalidad. Ha podido escribir Vittorio Bodini, el primer crítico riguroso de Larrea, cómo en su poesía «los sustantivos nacen simultáneamente con sus sorprendentes predicados, y esto es ya el signo de un poeta de raza» ${ }^{24}$.

24 Cf. Los poetas surrealistas españoles, Barcelona, Tusquets, 1971, p. 53. Alli mismo escribe Bodini: «Lo que más sorprende en las visiones o equivalencias de atmósferas que Larrea pesca del propio fondo es la extraordinaria aptitud de las cosas para realizar actos o probar sentimientos que estamos muy lejos de prever, pero que la fuerza de persuasión del poeta nos hace aceptar del modo más llano [...] Los predicados son acciones o relaciones entre las cosas: la tupidísima red que forman entre ellas hace que el universo de Larrea, unitario y sensible, se corresponda de una parte a otra, a punto siempre de registrar hasta las más insospechadas lontananzas, el más pequeño acontecimiento o la más pequeña coincidencia que se verifique en cualquier lugar. Un gesto pone en movimiento una multitud infinita de compensaciones, de equilibrios, de acuerdo con leyes desconocidas para nosotros, pero que adivinamos provistas de intima necesidad". Para Bodini, por otra parte, Larrea es poeta netamente surrealista. Nosotros hemos preferido, en virtud de importantes indicios ya señalados y en razón de que, sea como fuere, la primera fase de la poesía larreana es creacionista y en modo alguno surrealista, adoptar una postura mucho más objetiva por menos generalizadora, además de atenta a las opiniones del propio poeta. 
4. Acaso se pregunte el lector acerca de la extraña fortuna que ha tenido en su propio país una obra escrita hace tantos años, hasta ahora escasamente estudiada, considerada por pocos.

En 1950, Manuel Durán Gili se refirió a Larrea dentro de su libro El superrealismo en la poesía española contemporánea; otro tanto hace Luis Cernuda en Estudios sobre poesía española contemporánea (1957); e incluso Max Aub ya aludió al poeta, diez años antes que Cernuda, en La poesía española contemporánea. Sea dicho también que existieron otras alusiones, pero todavía más reducidas, asimismo anteriores. El hecho, por otra parte, es que la obra poética de Larrea no estaba disponible para el lector, y esto por reservas personales del propio poeta. Se había editado en 1934 Oscuro Dominio por mediación de Gerardo Diego, mas en Méjico y en tirada de cincuenta ejemplares. Es así que el acceso a la poesía larreana ha estado durante muchos años prácticamente limitado a los poemas introducidos por Diego en su famosa antología Poesía Española. La ruptura de tal estado de cosas se produjo en 1969, cuando Bodini consigue que el poeta acceda a la edición italiana de Versión Celeste en Torino. Al año siguiente llegaría la edición española. Por otro lado, la habitual indigencia gala para un propósito de esta índole no parece haya de acoger debidamente la obra escrita en lengua francesa por Larrea.

Sin contar con los poemas en distintas ocasiones aparecidos en revistas desde 1919 (Grecia, Cervantes, Carmen, Verso y Prosa, Litoral...), lo cierto es que la crítica dispuso en todo momento de las poesías recogidas por Diego en su antología citada, tan prestigiosa. ¿Por qué se silenció al exiliado Larrea quizás bajo el amparo de que no tenía «libro»? 